in the results of the demersal tows was Micromesistius poutassou $(190-200-43 \%$; $280-318-64 \% ; 397-414 \mathrm{~m}-50 \%$ ). This is understandable as $M$. poutassou is a predominantly pelagic slope-dweller $(300-500 \mathrm{~m}$ depth), but with a known tendency to impinge on the bottom where this traverses its depth distribution (Bailey 1982). No demersal species, on the other hand, were so ranked among the pelagic mid-Trough samples. Only in the pelagic tows over the slope were demersal species (three) present in sufficient proportion to warrant inclusion. Remembering the close proximity to the bottom of the pelagic trawl $(0-10 \mathrm{~m}-1$ tow; $3-18 \mathrm{~m}-7$ tows; $60 \mathrm{~m}-1$ tow) such a total is noteworthy. This is especially so when the nature of the species is considered. The most important contribution was by Halargyreus johnsonii (598-637m-12\%), Synaphobranchus kaupi $(8 \%)$ and Coryphaenoides rupestris (3\%, both in 794-841 m). Most $S$. kaupi were immediately post-metamorphic juveniles and the $H$. johnsonii were again juvenile, stages when both are more likely to occur well off the sea bed.

Despite the obvious limitations of this preliminary investigation with large nets, this is the first substantial observation that the bulk of the populations of demersal and pelagic species remain separate over the slope, with the swimming layers of the former evidently very close to the bottom. Additional, more detailed investigation would clearly be rewarding.

Bailey, R. S. 1982. The population of the blue whiting in the North Atlantic. Advances in Marine Biology 19, 257-355.

\title{
Growth rates of deep-sea benthic animals in the Rockall Trough
}

\author{
J. D. Gage \\ Dunstaffnage Marine Research Laboratory, P.O. Box 3, Oban, Argyll PA34 4AD, \\ Scotland
}

There has been a prevailing view that life processes are very slow in the deep sea. This is based on rather sparse data from in situ studies of the sediment, microbial and fish respiration, and sediment recolonisation. Other in situ recolonisation observations indicate that certain species may settle and grow within a year or two. Estimates of age and growth rate of individual species are few, frequently based on few data and present no clear pattern. A well-known study, by means of radiometric dating, providing an estimate of what is thought to be an exceptionally slow rate of growth in a small-sized species of protobranch bivalve is subject to wide confidence limits.

The discovery of seasonal breeding in deep-sea species of echinoderms and bivalves offers the possibility of tracking the growth of age-marked cohorts in a time series of samples. This approach has been applied to a long time series of deep-sea hauls obtained using an epibenthic sledge at the Scottish Marine Biological Association's Permanent Station in the southern Rockall Trough. In order to make estimates of cohort age structure, methods of analysing the modal structure of size-frequency distributions have been applied. However, both because of individual variation in growth rate and because of growth curves resulting in 
"stacked" frequencies of older age classes, such methods have only limited value. An approach utilising computer graphics in simulations of the growth and survivorship schedules through the life history of a species showing seasonal recruitment has been found to provide a powerful tool in developing likely hypotheses of age structure of deep-sea brittle stars, such as Ophiomusium lymani.

The development of such models is much aided by the discovering of skeletal markers in the form of annual banding in certain species. In the deep-sea echinoid Echinus affinis growth zones are evident in the plates of the test and in the jaw ossicles. Banding is present in the plates of even small, pre-reproductive stages. It is likely that such annual banding is the result of a seasonally varying growth rate as a result of the marked seasonal cycle in availability of a fallout of fast-sinking phytodetritus from the surface on which this urchin probably feeds. Counts of growth banding have provided a growth curve that, although indicating a slower growth and longer life span than inshore relatives, is not exceptional among certain other benthic species living in shallow-water.

Preliminary studies of growth rings on the shells of small, seasonally-breeding bivalves that are among the most abundant species living on the bottom, have suggested growth rates and generation times similar to those estimated from inshore relatives.

Overall, the analysis of population dynamics of deep-sea organisms from the time-series sampling offers little support for the notion of growth rates being generally low and life spans being exceptionally attenuated. It would seem reasonable to expect a mix of life-history strategies similar to that found in shallow water, and encompassing both slow and fast rates of population turnover, to occur in the deep sea.

\section{Shelf break faunas on the eastern margin of the Rockall Trough and Faeroe-Shetland Channel}

\section{J. B. Wilson and J. M. Desmond}

Institute of Oceanographic Sciences, Brook Road, Wormley, Godalming, Surrey GU8 5UB, U.K.

Investigations into the sediments and shell-bearing faunas on the upper continental slope, the shelf break and the outer parts of the continental shelf on the eastern margins of the Rockall Trough and Faeroe-Shetland Channel suggest that a distinctive faunal association can be recognised which is restricted to the shelf break.

The distributions of some thirty-seven species of molluscs, echinoderms, coelenterates (mostly corals) and crustaceans (barnacles) have suggested that the association contains three groups of species: shelf species which range over the shelf break and onto the upper slope, continental slope species whose upper depth limit reaches the shelf break and the outer parts of the continental shelf and a third group of species which is largely restricted to the shelf break. 